when a technical error was committed, often because of distraction. For example, one swallower lacerated his pharynx when trying to swallow a curved sabre, a second lacerated his oesophagus and developed pleurisy after being distracted by a misbehaving macaw on his shoulder, and a belly dancer suffered a major haemorrhage when a bystander pushed dollar bills into her belt causing three blades in her oesophagus to scissor. Of the 12 cases of probable perforation, including the two previously described in the literature, at least five involved the cervical or upper dorsal oesophagus with only one definite pharyngeal perforation. The other injuries were either lower down or the exact level of perforation was uncertain. All these patients survived, and no contacts of the association have died as a direct result of sword swallowing and no deaths have been reported in the medical literature. There is historical evidence elsewhere, however, and deaths from swallowing swords and other items such as neon tubes are described on the internet (www.swordswallow.com/ halloffame.php).

\section{Comparison with endoscopic injury}

The first endoscopy by Adolph Kussmaul in 1868 used mirrors and a gasoline lamp in a sword swallower, ${ }^{4}$ but rigid instruments, with their high rate of perforation, have largely been replaced. ${ }^{5}$ Patients injured during endoluminal procedures tend to be older and have pre-existing disease, the injuries usually complicating therapeutic manoeuvres. ${ }^{67}$ Iatrogenic perforation is sometimes not recognised until an instrument has passed well into the mediastinum of the patient, who is usually not fully conscious, and it tends to occur either adjacent to a lesion or where the pharynx narrows down to the oesophagus at or near Kilian's dehiscence. ${ }^{6}$ Most sword injuries were lower than this level, suggesting that the failure of a straight sword to negotiate the oesophageal lumen as it curves to fit the dorsal kyphosis may contribute to injury.

As in iatrogenic perforation, penetration is the main cause of injury but lacerations and scissoring injuries occur. A sword rarely passes out into the mediastinum and, although an injured swallower may realise that the performance has not proceeded smoothly, the injury may be recognised only when surgical emphysema, pain, or other symptoms develop, and there is often a delay before medical advice is sought.

Many factors, including delay and the size and site of the injury, have a bearing on outcomes. Mortality from iatrogenic perforation is quoted at $10-30 \%,{ }^{78}$ but we did not find any deaths from sword swallowing.

Our 46 respondents collectively had swallowed over 2000 swords in the three months before we contacted them but the complications relate to their professional lifetimes. Although the risk of sustaining life threatening injury is low for an experienced swallower while relaxed and concentrating on swallowing a single sword, the risk over a career is high. The prognosis for a sword swallower who does sustain upper gastrointestinal injury seems better than for patients who suffer iatrogenic perforation.

We thank Steven Kay of Manchester Business School for statistical help and members of the SSAI.

Contributors: BW is guarantor and designed the study. DM (Dan@swordswallow.com) has attended four international conventions arranged by the SSAI, maintains its archive, and has had contact with most known sword swallowers over several years.

Funding: None.

Competing interests: None declared.

Ethical approval: Not required.

1 Scheinin SA, Wells PR. Oesophageal perforation in a sword swallower. Tex Heart Inst J 2001;28:65-8.

2 Martin M, Steele S, Mullenix P, Long W, Izenberg S. Management of oesophageal perforation in a sword swallower: a case report and review of the literature. J Trauma 2005;59:233-5.

3 Devgan BK, Gross CW, McCloy RM, Smith C. Anatomic and physiological aspects of sword swallowing. Ear Nose Throat J 1978;57:445-50.

4 Huizinga E. On oesophagoscopy and sword-swallowing. Ann Otol Rhinol Laryngol 1969;78:32-9.

5 Kubba H, Spinou E, Brown D. Is same-day discharge suitable following rigid esophagoscopy? Ear Nose Throat J 2003;82:33-6.

6 Younes Z, Johnson DA. The spectrum of spontaneous and iatrogenic esophageal injury.J Clin Gastroenterol 1999;29:306-17.

7 Lawrence DR, Moxton RE, Fountain SW, Ohri SK, Townsend ER. Iatrogenic oesophageal perforations: a clinical review. Ann R Coll Surg Engl 1998;80:115-8.

8 Altorjay A, Kiss J, Voros A, Bohak A Nonoperative management of esophageal perforations. Ann Surg 1997;225:415-21. (Accepted 28 October 2006)

doi $10.1136 /$ bmj. 39027.676690 .55

\title{
You're not going to give me the umbrella, are you?
}

\author{
C Bradbeer, S Soni, A Ekbote, T Martin
}

Access to genitourinary clinics is a hot topic, and we have been working to encourage more men to present for screening for sexually transmitted infections. There is a long standing urban myth that men attending such clinics have to have the "umbrella test." This myth varies little in rendition. The usual description is that something akin to a cocktail umbrella in a closed position is inserted deep into the urethra. This umbrella is then opened out and withdrawn, to the considerable discomfort of the owner of said urethra.

The origins of this myth are obscure-although, no doubt, readers will enlighten us. In fact, asymptomatic men attending our clinic are checked for urethral infections by urine test only; symptomatic men have a swab tipped with cotton inserted a short distance into their urethra, which is relatively painless.

We needed to know if this myth was still prevalent and whether it was deterring patients from accessing our services.

\section{Methods}

To determine patients' expectations and whether action to dispel the myth is needed, we gave brief ques- 


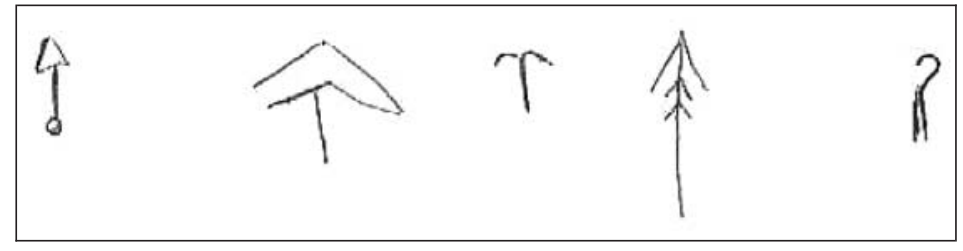

Examples of respondent's illustrations of the umbrella test

tionnaires to random male patients in the waiting room, asking what, if anything, they had heard about the umbrella test.

\section{Results}

Forty six questionnaires were completed and returned. In all, 28 men had attended a sexual health clinic before. Eighteen had heard of the myth. Fourteen said that the idea of an umbrella put them off coming to a clinic. Men who had heard of the myth and believed it were more likely to be white, heterosexual, and younger than 25 years old.

More than half the men stated that more advertising and publicity were needed to encourage men to go to clinics and felt that the media was a useful tool. Most wanted reassurance that the investigations to which they would be subjected would be painless. Some men illustrated their response with a description or sketch of the legendary instrument (figure).

\section{Conclusion}

The umbrella myth is still being promulgated. As a result of this work, we intend to focus on dispelling the

\section{Descriptions of the umbrella test}

- "a small scraping tool"

- "a McDonald's straw"

- "[the] dreadful part is the penis torture"

- "imagined it looking like a miniature cocktail umbrella"

- "something like a long probe, nothing too scary, even though I've heard it hurts a lot"

- "cylindrical with reversed spikes on it"

- "a small metal umbrella that's inserted into the end of the penis and then opened and dragged out to obtain cell samples"

myth within our clinic by putting up signs in the waiting room and ensuring that staff are aware of patients' fears. However, we feel that a wider refutation of the myth might encourage more men to seek screening for sexually transmitted infections. Although media attention has focused much on sexual health crises in recent years, more informative advertising and media attention is needed to encourage people to attend clinics.

Contributors: $\mathrm{CB}$ had the idea, oversaw the work, and wrote the paper. AE did the first draft of the questionnaire and first analysis of the results. SS redrafted the questionnaire, did the final analysis, and contributed to the final draft of the paper. TM commented on the questionnaire. All contributors distributed the questionnaire to the participants. $\mathrm{CB}$ is guarantor. Funding: None.

Competing interests: None declared.

Ethical approval: Not needed.

doi 10.1136/bmj.39043.717245.F7

\section{A day in the life of a doctor}

\section{The teleconference}

The main purpose of a teleconference is to provide protected time to answer emails. It is this, and not cicadas, which accounts for the continual clicking noise in the background of all teleconferences. The most recent email that you will find in your in tray is the agenda for the teleconference, plus multiple attachments, sent 30 seconds before the conference starts.

There are some important subsidiary functions of teleconferences. The first is professional interaction. You should arrange teleconferences as often as possible, involving colleagues from at least 20 countries spaced at least $1000 \mathrm{~km}$ apart. Start the teleconference at a time of your own maximum convenience. In this way you can ensure that your international academic rivals and their immediate family are sleep deprived for much of the year.

You can also ensure that your academic rivals believe that their faculties are waning, by placing the microphones at a distance from the participants, which ensures that any conversation is audible only to someone with the hearing of a bat. Meanwhile, by taking teleconference calls at home with the door open, allowing them to hear loud squeals of merriment from your children, you provide evidence of your fecundity and your ability to work efficiently from home.

The etiquette for a teleconference is a hybrid of the English class and the Indian caste systems. Roles are carefully delineated. The chairperson's role is to conduct the teleconference with all the subtlety of Senator McCarthy investigating Communist subversion. The most seasoned clinician is invited for political reasons. He (it is always a he) wanders in and out of the room, pontificating on previously resolved agenda items and laughing at his own jokes in a fatherly way because no one else finds them funny. Workload is inversely related to age: the youngest member organises the time of the teleconference, sets the agenda, and writes the minutes.

The role of the telecommunication company is to forget to ring all the most important people on time, and then to interrupt the meeting periodically with ear splitting bleeps and say, "Excuse the interruption, but Dr Livingstone has just presumed to join the teleconference."

Communication is not one of the purposes of a teleconference. The most refined form of teleconference is a videoconference. The main purpose of a videoconference is to make sure you do not answer your emails.

David Isaacs senior staff specialist, Department of Immunology and Infectious Diseases, Children's Hospital at Westmead, Sydney, Australia (davidi@chw.edu.au),Stephen Isaacs consultant, Waltham Forest Child and Family Consultation Service, London, Dominic

Fitzgerald senior staff specialist, Department of Respiratory Medicine, Children's Hospital at Westmead 